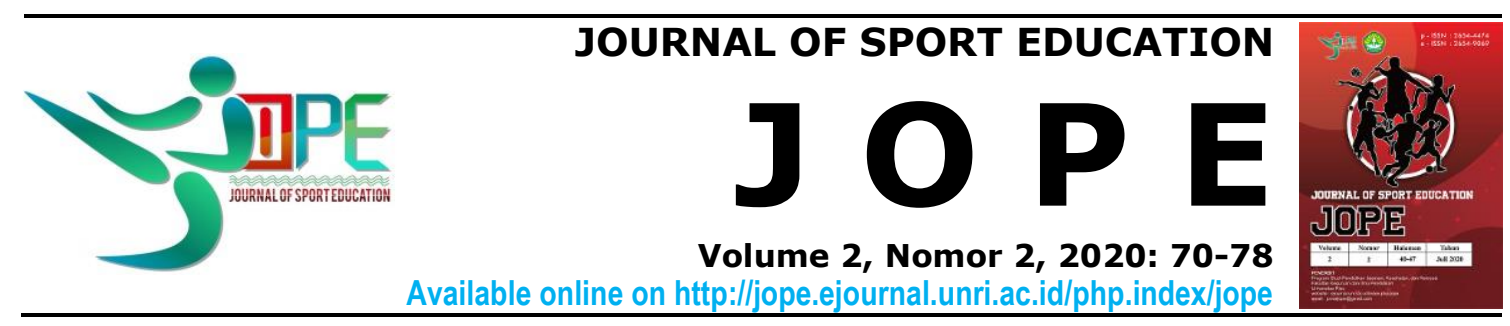

\title{
Motivasi siswa mengikuti kegiatan ekstrakurikuler bola basket di smp negeri 9 pekanbaru
}

\author{
Oki Candra ${ }^{1}$, Wahyudi ${ }^{2}$ \\ ${ }^{1,2}$ Universitas Islam Riau \\ okicandra@edu.uir.ac.id¹,uwah26@gmail.com²
}

Received: 11 Desember 2019; Revised: 3 Juni 2020; Accepted: 16 Juni 2020

doi http://dx.doi.org/10.31258/jope.2.2.70-78

\begin{abstract}
Abstrak
Tujuan penilitian ini adalah untuk mengetahui motivasi siswa dalam mengikuti kegiatan ekstrakurikuler yang dilaksanakan di SMP Negeri 9 Pekanbaru, penelitian ini juga bertujuan untuk melihat pola pikir anak terhadap apa yang didapat dilapangan selama mengikuti kegiatan ekstrakurikuler dan juga menjadi acuan bagi pelatih untuk memberikan pembelajaran yang efektif sewaktu kegiatan ekstrakurikuler. Adapun metode yang digunakan dalam penelitian ini adalah penyebaran angket terhadap siswa ekstrakurikuler SMP negeri 9 Pekanbaru. Dari data yang diperoleh, indikator kebutuhan tingkat pencapaian sebesar 90,72\% dalam kategori sangat tinggi, indikator bakat tingkat pencapaian $73,33 \%$ dalam kategori Tinggi, indikator keterampilan tingkat pencapaian $82,42 \%$ dalam kategori Sangat Tinggi, indikator teman tingkat pencapaian $73,33 \%$ dalam kategori Tinggi, indikator sarana dan prasarana tingkat pencapaian 73,14\% dalam kategori Tinggi, indikator guru tingkat pencapaian 90,09\% dalam kategori Sangat Tinggi, indikator lingkungan tingkat pencapaian 75,49\% dalam kategori Tinggi.
\end{abstract}

Kata Kunci: siswa, motivasi, ekstrakurikuler, bolabasket

\section{Student motivation in basketball extracurricular activities at smp negeri 9 pekanbaru}

\begin{abstract}
The purpose of this research is to study students in participating in extracurricular activities carried out at SMP Negeri 9 Pekanbaru, this study also aims to look at the mindset of children towards what is obtained in the field while studying extracurricular activities and also to seek help to help helpful learning. extracurricular activities. The method used in this study is the distribution of questionnaires to extracurricular students of SMP Negeri 9 Pekanbaru. From the data obtained, an indicator of the level of need obtained by $90.72 \%$ in the very high category, an indicator of talent attainment level of $73.33 \%$ in the High category, an indicator of skill achievement level of $82.42 \%$ in the Very High category, a friend indicator of achievement level of $73,33 \%$ in the High category, facilities and infrastructure indicators of achievement level $73.14 \%$ in the High category, indicators of teachers achievement level of $90.09 \%$ in the Very High category, environmental indicators of the acquisition rate of $75.49 \%$ in the High category.
\end{abstract}

Keywords: student, motivation, extracurricular, basketball

How To Cite: Candra, Oki \& Wahyudi. (2020). Motivasi siswa mengikuti kegiatan ekstrakurikuler bola basket di smp negeri 9 pekanbaru. Journal of Sport Education (JOPE), 2 (2), 70-78. 
Journal of Sport Education (JOPE), 2 (2) 2020 - 71

Oki Candra ${ }^{1}$,Wahyudi ${ }^{2}$

\section{PENDAHULUAN}

Pendidikan yang baik dan bermutu akan menghasilkan manusia yang berkualitas sesuai dengan tujuan pendidikan nasional. Maka, dapat dikatakan bahwa tujuan pendidikan pada dasarnya adalah untuk meningkatkan sumber daya manusia. Salah satu upaya untuk meningkatkan kualitas sumber daya manusia tersebut adalah melalui pendidikan jasmani olahraga.

Secara umum, mayoritas orang memahami bahwa olahraga merupakan salah

satu aktivitas jasmani oleh sekelompok orang dengan tujuan untuk menciptakankebugaran jasmani. Aktivitas olahraga dilakukan oleh semua orang tanpa melihat perbedaan usia. Sehingga olahraga berpotensi memengaruhi pembentukan karakter individu yang ada di dalamnya. Olahraga sebagai saran untuk mengembangkan potensi jasmani, rohani, dan sosial.

Pendidikan jasmani olahraga dan kesehatan merupakan wahana untuk mendidik anak. Melalui pendidikan jasmani olahraga dan kesehatan diharapkan siswa mampu meningkatkan kreativitas, inovatif, dan keterampilan dalam melakukan aktivitas jasmani. Untuk mencapai tujuan dalam pelaksanaan pendidikan jasmani bukan hanya di jam sekolah saja tapi juga di jam tambahan di luar sekolah yaitu namanya ekstrakurikuler.

Ekstrakurikuler bertujuan sebagai wadah bagi siswa dalam mengembangkan bakat, kemampuan, dan prestasi pada bidang yang mereka sukai. Menurut (Mailani, 2016) Ekstrakurikuler adalah kegiatan yang dilakukan siswa sekolah atau di luar jam belajar kurikulum standar. Kegiatan ekstrakurikuler merupakan kegiatan pendidikan di luar jam pelajaran untuk membamtu pengembangan peserta didik sesuai dengan kebutuhan, potensi, bakat dan minat siswa melalui kegiatan yang secara khusus diselenggarakan oleh pendidik dan tenaga kependidikan yang berkemampuan dan berkewenangan di sekolah.

Jadi beradasarkan pendapat di atas ekstrakurikuler merupakan kegiatan tambahan di luar jam sekolah untuk mendukung dan mengembangkan potensi anak dalam pembinaan satu cabang olahraga. Pembinaan di luar jam jam sekolah merupakan salah satu untuk menambah suatu wawasan yaitu salah satunya dalam olahraga bola basket.

Menurut (Nugraha, P. D., \& Pratama, 2019) Olahraga bola basket adalah suatu permainan yang dimainkan secara tim yang setiap tim terdiri dari 5 orang,sehingga diperlukan suatukerjasama tim dan keterampilan dari masing masing individu. Sedangkan menurut (Candra, 2017) bola basket adalah permainan tim, namun penguasaan teknik individual sangatlah penting sebelum bermain di dalam tim. Hal yang sama di sampaikan oleh (Hidayatullah, 2018) bola basket merupakan cabang olahraga yang cukup kompleks dimana melibatkan berbagai aspek kebugaran jasmani di dalamnya. Beberapa penelitian sebelumnya yang membahas tentang aspek kebugaran/fisik yang harus dikuasai secara dominan untuk 


\section{Journal of Sport Education (JOPE), 2 (2) 2020 - 72}

\section{Oki Candra ${ }^{1}$, Wahyudi ${ }^{2}$}

dapat tampil lebih baik dari lawannya atau sekedar meningkatkan performa terbaiknya. Pendapat di atas menjelaskan bahwa bola basket adalah olahraga berkelompok yang dimainkan oleh 5 orang dengan tujuan untuk memasukkan bola sebanyakbanyaknya kekeranjang lawan dan menghalangi lawan untuk mencetak skor dan juga olahraga yang membutuhkan kondisi fisik yang prima dan teknik yang benar.

Pada dasarnya seseorang melakukan aktivitas kegiatan ekstrakurikuler atau tingkah laku selalu didasari dengan adanya motivasi. Semakin besar motivasi seseorang dalam melakukan aktivitas atau tingkah laku, maka semakin besar pula kemungkinan orang tersebut mencapai keberhasilan dan kesuksesan. Sebaliknya semakin kecil motivasi seseorang dalam melakukan aktivitas atau tingkah laku, maka semakin kecil pula kemungkinan untuk meraih keberhasilan dan juga kesuksesan. Jadi, motivasi diperlukan untuk mencapai keberhasilan dan kesuksesan terutama kegiatan olahraga di sekolah guna mencapai prestasi.

Di dalam hal ini untuk mengikuti ektrakurikuler bola basket kita juga harus memiliki motivasi yang inginkan, bagaiamana di jam ektrakurikuler siswa bisa lebih termotivasi dalam keinginan yang kuat. Motivasi dilandasari oleh kemauan dan keinginan pribadi untuk mencapai sesuatu yang diinginkan, dalam hal ini motivasi yang dilihat melalui ekstrakurikuler yang bertujuan untuk mengembangkan potensi anak untuk mengikuti kegiatan ekstrakurikuler tersebut.

Motivasi merupakan proses aktualisasi sumber penggerak dan pendorong tingkah laku individu memenuhi kebutuhan untuk mencapai tujuan tertentu. Motivasi olahraga diartikan keseluruhan daya penggerak (motif-motif) di dalam diri individu yang menimbulkan kegiatan berolahraga, menjamin kelangsungan latihan dan memberi arah pada kegiatan latihan untuk mencapai tujuan yang dikehendaki (Effendi, 2016). Sedangkan menurut pendapat (Gillet et al., 2010) motivation leadsto affective, cognitive, and behavioral consequences. teori di atas menjelaskan bahwa motivasi merupakan sikap, pengetahuan dan tingkah laku seseorang yang ada pada manusia.

Menurut (Oktavian, 2015) motivasi adalah daya penggerak yang telah menjadi aktif. Motivasi menjadi aktif ketika pada saat tertentu, bila kebutuhan untuk mencapai tujuan sangat dirasakan/ dihayati. Tidak jauh berbeda yang di sampaikan oleh (Aritonang, 2008) motivasi merupakan suatu daya atau kekuatan yang timbul dari dalam diri siswa untuk memberikan kesiapan agar tujuan yang telah ditetapkan tercapai. Dalam hal ini motivasi juga bisa dating dalam diri kita ataupun bisa juga datang dari luar diri kita seperti teori di bawah ini (Yuliasari, 2013) motivasi intrinsik adalah dorongan yang berasal dari dalam individu untuk melakukan sesuatu karena individu tersebut menikmatinya dan individu tersebut tidak memerlukan rangsangan dari luar untuk melakukannya, sedangakan motivasi ekstrinsik adalah 
Journal of Sport Education (JOPE), 2 (2) 2020 - 73

Oki Candra ${ }^{1}$, Wahyudi ${ }^{2}$

dorongan atau motif yang berasal dari luar

individu untuk melakukan sesuatu, karena adanya rangsangan dari luar atau tujuan yang ingin dicapai. Macam-macam motivasi ekstrinsik terdiri dari aspek penghargaan, aspek persaingan/kompetisi, aspek hadiah, aspek pujian, aspek hukuman, dan aspek lingkungan.

Di era yang modern seperti sekarang ini, olahraga membutuhkan pendekatan emosional yang baik, jadi agar tercapainya tujuan pembelajaran pendidikan jasmani seperti yang diinginkan, guru/pelatih dituntut untuk mampu memberikan rangsangan serta motivasi yang baik kepada siswa/siswi agar mampu menumbuh kembangkan potensi anak yang dimiliki terkhusus dalam bidang olahraga bola basket.

\section{METODE}

Penelitian ini menggunakan jenis penelitian dengan pendekatan deskriptif kuantitatif (Yusuf, Muhammad \& Kartiko, 2014). Jenis penelitian ini diharapkan dapat mengurai gambaran tingkat motivasi siswa terhadap kegiatan ekstrakurikuler bola basket di SMP Negeri 9 Pekanbaru. Jenis penelitian ini diharapkan dapat mengurai gambaran tingkat motivasi siswa terhadap kegiatan ekstrakurikuler bola basket di SMP Negeri 9 Pekanbaru. Populasi dalam penelitian ini adalah seluruh siswa ekstrakurikuler bola basket di SMP Negeri 9 Pekanbaru sebanyak 51 orang putera dan puteri. Adapun teknik pengumpulan sampel yaitu menggunakan total sampling yang berjumlah 51 orang.

Adapun indikator angket dalam motivasi ini terbagi atas dua factor yaitu instrinsik dan ekstrinsik, berikut tabelnya di bawah ini:

Tabel 1. Indikator Angket

\begin{tabular}{lll}
\hline Variabel & Faktor & Indikator \\
\hline \multirow{3}{*}{ Motivasi } & Instrinsik & Kebutuhan \\
\cline { 3 - 3 } & & Bakat \\
\cline { 3 - 3 } & \multirow{2}{*}{ Ekstrinsik } & Keterampilan \\
\cline { 3 - 3 } & & Teman \\
\cline { 3 - 3 } & & Sarana dan prasarana \\
\cline { 3 - 3 } & &
\end{tabular}

HASIL DAN PEMBAHASAN

\section{Hasil}

\section{Indikator Kebutuhan}

Aspek indikator kebutuhan dalam penelitian ini, dengan 51 orang siswa yang mengikuti ekstrakurikuler bola basket SMP Negeri 9 Pekanbaru sebagai responden telah memberikan jawaban terhadap angket yang diberikan, dari 37 pernyataan pada indikator kebutuhan didapat siswa yang menjawab
Sangat Setuju (SS) sebanyak 166 total skor 664 dengan persentase $71,47 \%$, Setuju (S) sebanyak 87 total 261 dengan persentase 28,09, Tidak Setuju (TS) sebanyak 2 total skor 4 dengan persentase $0.44 \%$, Sangat Tidak Setuju (STS) Sebanyak 0 total 0 dengan persentase 0\%. Pada indikator ini tingkat pencapaian sebesar 90,72\%, temasuk dalam kategori "Sangat Tinggi”. 
Journal of Sport Education (JOPE), 2 (2) 2020 - 74

Oki Candra ${ }^{1}$, Wahyudi ${ }^{2}$

Tabel 2. Indikator Kebutuhan

\begin{tabular}{cccccc}
\hline Jawaban & Nilai & $\begin{array}{c}\text { Jumlah } \\
\text { Jawaban }\end{array}$ & $\begin{array}{c}\text { Total } \\
\text { Skor }\end{array}$ & $\begin{array}{c}\text { Frekuensi } \\
\text { Relatif }\end{array}$ & $\begin{array}{c}\text { Tingkat } \\
\text { Pencapaian }\end{array}$ \\
\cline { 1 - 5 } Sangat Setuju & 4 & 166 & 664 & $71,47 \%$ & \\
\cline { 1 - 4 } Setuju & 3 & 87 & 261 & $28,09 \%$ & \\
\cline { 1 - 4 } Tidak Setuju & 2 & 2 & 4 & $0,44 \%$ & \\
\cline { 1 - 4 } Sangat Tidak Setuju & 1 & 0 & 0 & & \\
\cline { 1 - 4 } Jumlah & 255 & 929 & $100 \%$ & \\
\cline { 1 - 4 }
\end{tabular}

\section{Indikator Bakat}

Aspek indikator bakat dalam penelitian ini, dengan 51 orang siswa yang mengikuti ekstrakurikuler bola basket SMP Negeri 9 Pekanbaru sebagai responden telah memberikan jawaban terhadap angket yang diberikan, dari 37 pernyataan pada indikator bakat didapat siswa yang menjawab Sangat Setuju (SS) sebanyak 122 total skor 488 dengan persentase $64,98 \%$, Setuju (S) sebanyak 77 total 231 dengan persentase 30,75\% Tidak Setuju (TS) sebanyak 16 total skor 32 dengan persentase 4,27\%, Sangat Tidak Setuju (STS) Sebanyak 0 total 0 dengan persentase $0 \%$. Pada indikator ini tingkat pencapaian sebesar 73,33\%, temasuk dalam kategori "Tinggi”. Untuk lebih jelasnya dapat dilihat dari tabel 3.

Tabel 3. Indikator Bakat

\begin{tabular}{cccccc}
\hline Jawaban & Nilai & $\begin{array}{c}\text { Jumlah } \\
\text { Jawaban }\end{array}$ & $\begin{array}{c}\text { Total } \\
\text { Skor }\end{array}$ & $\begin{array}{c}\text { Frekuensi } \\
\text { Relatif }\end{array}$ & $\begin{array}{c}\text { Tingkat } \\
\text { Pencapaian }\end{array}$ \\
\cline { 1 - 5 } Sangat Setuju & 4 & 122 & 488 & $64,98 \%$ & \\
\cline { 1 - 4 } Setuju & 3 & 77 & 231 & $30,75 \%$ & \\
\cline { 1 - 4 } Tidak Setuju & 2 & 16 & 32 & $4,27 \%$ & \\
\cline { 1 - 4 } Sangat Tidak Setuju & 1 & 0 & 0 & $0 \%$ & \\
\cline { 1 - 4 } Jumlah & 215 & 751 & $100 \%$ & \\
\cline { 1 - 4 } & & & &
\end{tabular}

\section{Indikator Keterampilan}

Indikator keterampilan dalam penelitian ini, dengan 51 orang siswa yang mengikuti ekstrakurikuler bola basket telah memberikan jawaban angke, sebanyak 37 pernyataan pada indikator keterampilan dengan Sangat Setuju sebanyak 108 total skor $522(61,84 \%)$, Setuju sebanyak 94 total $282(33,42 \%)$ Tidak Setuju sebanyak 20 total skor $40(4,74 \%)$, Sangat Tidak Setuju Sebanyak 0 total $0(0 \%)$. Pada indikator ini tingkat pencapaian sebesar $82,42 \%$, temasuk dalam kategori "Sangat Tinggi".

Tabel 4. Indikator Keterampilan

\begin{tabular}{cccccc}
\hline Jawaban & Nilai & $\begin{array}{c}\text { Jumlah } \\
\text { Jawaban }\end{array}$ & $\begin{array}{c}\text { Total } \\
\text { Skor }\end{array}$ & $\begin{array}{c}\text { Frekuensi } \\
\text { Relatif }\end{array}$ & $\begin{array}{c}\text { Tingkat } \\
\text { Pencapaian }\end{array}$ \\
\cline { 1 - 5 } Sangat Setuju & 4 & 108 & 522 & $61,84 \%$ & \\
\cline { 1 - 4 } Setuju & 3 & 94 & 282 & $33,42 \%$ & \\
\cline { 1 - 4 } Tidak Setuju & 2 & 20 & 40 & $4,74 \%$ & \\
\cline { 1 - 4 } Sangat Tidak Setuju & 1 & 0 & 0 & $0 \%$ & \\
\cline { 1 - 4 } Jumlah & 222 & 844 & & \\
\cline { 1 - 4 } & & & &
\end{tabular}

\section{Indikator Teman}


Journal of Sport Education (JOPE), 2 (2) 2020 - 75

Oki Candra ${ }^{1}$, Wahyudi ${ }^{2}$

Aspek indikator teman dalam penelitian ini, dengan 51 orang siswa yang mengikuti ekstrakurikuler bola basket SMP Negeri 9 Pekanbaru sebagai responden telah memberikan jawaban terhadap angket yang diberikan, dari 37 pernyataan pada indikator teman didapat siswa yang menjawab Sangat Setuju (SS) sebanyak 143 total skor 572 dengan persentase $64,98 \%$, Setuju (S) sebanyak 120 total 360 dengan persentase 30,75\% Tidak Setuju (TS) sebanyak 29 total skor 58 dengan persentase 4,27\%, Sangat Tidak Setuju (STS) Sebanyak 14 total 14 dengan persentase 1,86\%. Pada indikator ini tingkat pencapaian sebesar $73,33 \%$, temasuk dalam kategori "Tinggi". Untuk lebih jelasnya dapat dilihat dari tabel berikut:

Tabel 5. Indikator Teman

\begin{tabular}{cccccc}
\hline Jawaban & Nilai & $\begin{array}{c}\text { Jumlah } \\
\text { Jawaban }\end{array}$ & $\begin{array}{c}\text { Total } \\
\text { Skor }\end{array}$ & $\begin{array}{c}\text { Frekuensi } \\
\text { Relatif }\end{array}$ & $\begin{array}{c}\text { Tingkat } \\
\text { Pencapaian }\end{array}$ \\
\cline { 1 - 5 } Sangat Setuju & 4 & 143 & 572 & $64,98 \%$ & \\
\cline { 1 - 4 } Setuju & 3 & 120 & 360 & $30,75 \%$ & \\
\cline { 1 - 4 } Tidak Setuju & 2 & 29 & 58 & $4,27 \%$ & \\
\cline { 1 - 4 } Sangat Tidak Setuju & 1 & 14 & 14 & $0 \%$ & \\
\cline { 1 - 4 } Jumlah & 306 & 751 & $100 \%$ & \\
\cline { 1 - 4 } & & & & &
\end{tabular}

\section{Indikator Sarana Dan Prasarana}

Aspek indikator sarana dan prasarana dalam penelitian ini, dengan 51 orang siswa yang mengikuti ekstrakurikuler bola basket SMP Negeri 9 Pekanbaru sebagai responden telah memberikan jawaban terhadap angket yang diberikan, dari 37 pernyataan pada indikator sarana dan prasarana didapat siswa yang menjawab Sangat Setuju (SS) sebanyak 92 total skor 368 dengan persentase 49,13\%, Setuju (S) sebanyak 113 total 339 dengan persentase 45,26\% Tidak Setuju (TS) sebanyak 28 total skor 20 dengan persentase 2,67\%, Sangat Tidak Setuju (STS) Sebanyak 22 total 22 dengan persentase $2,93 \%$. Pada indikator ini tingkat pencapaian sebesar $73,14 \%$, temasuk dalam kategori "Tinggi". Untuk lebih jelasnya dapat dilihat dari tabel berikut:

Tabel 6. Indikator Sarana dan Prasarana

\begin{tabular}{cccccc}
\hline Jawaban & Nilai & $\begin{array}{c}\text { Jumlah } \\
\text { Jawaban }\end{array}$ & $\begin{array}{c}\text { Total } \\
\text { Skor }\end{array}$ & $\begin{array}{c}\text { Frekuensi } \\
\text { Relatif }\end{array}$ & $\begin{array}{c}\text { Tingkat } \\
\text { Pencapaian }\end{array}$ \\
\cline { 1 - 4 } Sangat Setuju & 4 & 92 & 368 & $49,13 \%$ & \\
\cline { 1 - 4 } Setuju & 3 & 113 & 339 & $45,26 \%$ & \\
\cline { 1 - 4 } Tidak Setuju & 2 & 28 & 20 & $2,67 \%$ & \\
\cline { 1 - 4 } Sangat Tidak Setuju & 1 & 22 & 22 & $2,93 \%$ & \\
\cline { 1 - 4 } Jumlah & & 255 & 749 & $100 \%$ & \\
\cline { 1 - 3 }
\end{tabular}

\section{Indikator Guru}

Aspek indikator guru dalam penelitian ini, dengan 51 orang siswa yang mengikuti ekstrakurikuler bola basket SMP Negeri 9 Pekanbaru sebagai responden telah memberikan jawaban terhadap angket yang diberikan, dari 37 pernyataan pada indikator guru didapat siswa yang menjawab Sangat Setuju (SS) sebanyak 154 total skor 616 dengan persentase $67,02 \%$, Setuju (S) 
Journal of Sport Education (JOPE), 2 (2) 2020 - 76

Oki Candra ${ }^{1}$, Wahyudi ${ }^{2}$

sebanyak 101 total 303 dengan persentase 32,98\% Tidak Setuju (TS) sebanyak 0 total skor 0 dengan persentase 0\%, Sangat Tidak Setuju (STS) Sebanyak 0 total 0 dengan persentase $0 \%$. Pada indikator ini tingkat pencapaian sebesar $90,09 \%$, temasuk dalam kategori "Sangat Tinggi". Untuk lebih jelasnya dapat dilihat dari tabel berikut:

Tabel 7. Indikator Guru

\begin{tabular}{cccccc}
\hline Jawaban & Nilai & $\begin{array}{c}\text { Jumlah } \\
\text { Jawaban }\end{array}$ & $\begin{array}{c}\text { Total } \\
\text { Skor }\end{array}$ & $\begin{array}{c}\text { Frekuensi } \\
\text { Relatif }\end{array}$ & $\begin{array}{c}\text { Tingkat } \\
\text { Pencapaian }\end{array}$ \\
\cline { 1 - 5 } Sangat Setuju & 4 & 154 & 616 & $67,02 \%$ & \\
\cline { 1 - 4 } Setuju & 3 & 101 & 303 & $32,98 \%$ & \\
\cline { 1 - 4 } Tidak Setuju & 2 & 0 & 0 & $0 \%$ & \\
\cline { 1 - 4 } Sangat Tidak Setuju & 1 & 0 & 0 & $0 \%$ & \\
\cline { 1 - 4 } Jumlah & & 255 & 919 & $100 \%$ & \\
\cline { 1 - 4 } & & & &
\end{tabular}

\section{Indikator Lingkungan}

Aspek indikator lingkungan dalam penelitian ini, dengan 51 orang siswa yang mengikuti ekstrakurikuler bola basket SMP Negeri 9 Pekanbaru sebagai responden telah memberikan jawaban terhadap angket yang diberikan, dari 37 pernyataan pada indikator lingkungan didapat siswa yang menjawab Sangat Setuju (SS) sebanyak 92 total skor 366 dengan persentase 39,61\%,
Setuju (S) sebanyak 176 total 488 dengan persentase $52,81 \%$ Tidak Setuju (TS) sebanyak 42 total skor 66 dengan persentase $7,14 \%$, Sangat Tidak Setuju (STS) Sebanyak 4 total 4 dengan persentase $0,44 \%$. Pada indikator ini tingkat pencapaian sebesar 75,49\%, temasuk dalam kategori "Tinggi”. Untuk lebih jelasnya dapat dilihat dari tabel berikut:

Tabel 8. Indikator Lingkungan

\begin{tabular}{cccccc}
\hline Jawaban & Nilai & $\begin{array}{c}\text { Jumlah } \\
\text { Jawaban }\end{array}$ & $\begin{array}{c}\text { Total } \\
\text { Skor }\end{array}$ & $\begin{array}{c}\text { Frekuensi } \\
\text { Relatif }\end{array}$ & $\begin{array}{c}\text { Tingkat } \\
\text { Pencapaian }\end{array}$ \\
\cline { 1 - 5 } Sangat Setuju & 4 & 92 & 366 & $39,61 \%$ & \\
\cline { 1 - 4 } Setuju & 3 & 176 & 488 & $52,81 \%$ & \\
\cline { 1 - 4 } Tidak Setuju & 2 & 42 & 66 & $7,14 \%$ & \\
\cline { 1 - 4 } Sangat Tidak Setuju & 1 & 4 & 4 & $0,44 \%$ & \\
\cline { 1 - 4 } Jumlah & & 314 & 924 & $100 \%$ & \\
\cline { 1 - 4 } & & & & &
\end{tabular}

\section{Pembahasan}

Dari hasil penelitian yang telah dilakukan bahwa motivasi dapat diartikan sebagai aktualisasi dari daya kekuatan dalam diri individu yang dapat mengaktifkan dan mengarahkan perilaku yang merupakan perwujudan dari interaksi terpadu antara motif $\mathrm{dm}$ need dengan situasi yang diamati dan dapat berfungsi untuk mencapai tujuan yang diharapkan individu, yang berlangsung dalam suatu proses yang dinamis.

Motivasi merupakan proses yang menjelaskan intensitas, arah, dan ketekunan seorang individu untuk mencapai tujuan. Artinya motivasi adalah alasan yang mendasari sebuah perbuatan yang dilakukan oleh seorang individu. Seseorang dikatakan memiliki motivasi tinggi dapat diartikan orang tersebut memiliki alasan yang sangat 
Journal of Sport Education (JOPE), 2 (2) 2020 - 77

Oki Candra $^{1}$, Wahyudi ${ }^{2}$

kuat untuk mencapai apa yang dinginkan. Inti definisi yang dikemukakan diinginkannya dengan mengerjakan pekerjaannya yang sekarang sebagaimana yang di jelaskan oleh (Widya Nurkusuma, 2017) motivasi merupakan energi dalam diri seseorang yang ditandai dengan munculnya "feeling" dan didahului dengan tanggapan terhadap adanya tujuan.

(Bolduc, 2000) the more discomfort you can create, the more motivation you have. Why? Wherever it is more comfortable for you to be, is where you will choose to be. But if it becomes uncomfortable to fail, you will stay committed to your goals. Teori yang disampaikan di atas menjelaskan bahwa semakin banyak ketidaknyamanan diciptakan, semakin banyak motivasi yang Anda miliki. Di mana pun lebih nyaman bagi Anda, inilah tempat yang Anda pilih. Tetapi jika menjadi tidak nyaman untuk gagal, Anda tetap berkomitmen pada tujuan Anda. (Prihartanta, 2015) menjelaskan bahwa peran motivasi dalam proses pembelajaran, motivasi belajar mahasiswa dapat dianalogikan sebagai bahan bakar untuk menggerakkan mesin motivasi belajar, mendorong siswa berperilaku aktif untuk berprestasi di dalam kelas, tetapi motivasi yang terlalu kuat justru dapat berpengaruh negatif terhadap keefektifan usaha belajar siswa, dikarenakan perlu jangka waktu untuk meresapi, menghayati dan melakukan bagaimana teori motivasi tersebut bisa diterapkan didalam kehidupan sehari-hari khususnya dalam hal pendidikan.

Motivasi tercipta pada diri seseorang guna mendorong mencapai suatu tujuan yang 


\section{DAFTAR PUSTAKA}

Aritonang, K. T. (2008). Minat dan Motivasi dalam Meningkatkan Hasil Belajar Siswa. Jurnal Pendidikan Penabur, 7(10), 11-21.

Bolduc, M. (2000). Of Motivation (Issue March). Guaranteed Success Strategies.

Candra, O. (2017). Pengaruh Metode Kooperatif Terhadap Keterampilan Lay Up Shoot Bola Basket Pada Siswa Puteri Kelas VIII Di SMP Negeri 9 Pekanbaru. Journal Sport Area, 2(1), 45-52.

Effendi, H. (2016). Peranan psikologi olahraga dalam meningkatkan prestasi atlet. Nusantara (Jurnal Ilmu Pengetahuan Sosial, 1, 23-30. https://doi.org/http://jurnal.umtapsel.ac.id/index.php/nusantara/articl e/view/90/90

Gillet, N., Vallerand, R. J., Amoura, S., \& Baldes, B. (2010). Influence of coaches' autonomy support on athletes' motivation and sport performance: A test of the hierarchical model of intrinsic and extrinsic motivation. Journal Psychology of Sport and Exercise, 11(2), 155-161. https://doi.org/10.1016/j.psychsport.2 009.10.004

Hidayatullah, F. (2018). Hubungan Kelincahan Dengan Keterampilan Menggiring Bola Basket Mahasiswa Baru Program Studi Pendidikan Olahraga STKIP PGRI Bangkalan. Journal Sport Area, 3(1), 28. https://doi.org/10.25299/sportarea.201 8.vol3(1).1555

Mailani, A. (2016). Tingkat Keterampilan Bermain Futsal Peserta Didik Putera yang Mengikuti Ekstrakurikuler di SMA Negeri 1 Imogiri Bantul. Pendidikan Jasmani Kesehatan Dan Rekreasi, 5(4), 1-8. http://journal.student.uny.ac.id/ojs/ojs/ index.php/pjkr/article/view/2350

Nugraha, P. D., \& Pratama, E. B. (2019). Survei Pembinaan Prestasi Atlet Bolabasket Kelompok Umur Di Bawah 16 Dan 18 Tahun. Journal
Sport Area, 4(1), 240-247.

Oktavian, O. (2015). Pengaruh Penyelenggaraan Unesa Cup Basket Terhadap Motivasi Siswa Dalam Mengikuti Ekstrakurikuler Bola Basket. Jurnal Pendidikan Olahraga Dan Kesehatan, 03(1), 132-134.

Prihartanta, W. (2015). Teori-Teori Motivasi. Jurnal Adabiya, 1(83), 111.

Widya Nurkusuma, T. (2017). Penerapan Permainan Kecil Terhadap Motivasi Belajar Siswa Dalam Pembelajaran Pendidikan Jasmani, Olahraga Dan Kesehatan Pada Siswa Kelas V Sdn Babatan 5 Kecamatan Wiyung Surabaya. Jurnal Pendidikan Olahraga Dan Kesehatan, 5(1), 110116.

Yuliasari, A. (2013). Peran Dominan Mitivasi Intrinsik dan Motivasi Ekstrinsik Siswa Putri Dalam Mengikuti Kegiatan Ekstrakurikuler Futsal (Studi pada SMA Dr. Soetomo Surabaya). Jurnal Pendidikan Olahraga Dan Kesehatan, 1(2), 314317.

Yusuf, Muhammad \& Kartiko, D. C. (2014). Motivasi Siswa Dalam Mengikuti kegiatan Ekstrakurikuler Bola Basket Di SMPN Se-Kecamatan Kuterejo Mojokerto. Jurnal Pendidikan Olahraga Dan Kesehatan, 02(02), 493-500. 